\title{
Interatividade push-button: elaborações de principais automatizações e suas variadas aplicações em equipamentos demonstrativos de museus de ciência e tecnologia
}

\author{
Interactive push-button: elaborations main automation and \\ miscellaneous applications equipment statements of museums of \\ science and technology
}

\author{
Osmar Henrique Moura da Silva ${ }^{1}$; Amarildo Ramos de Almeida ${ }^{2}$; Eliana Aparecida \\ Silicz Bueno ${ }^{3}$; Irinéa de Lourdes Batista ${ }^{4}$
}

\section{Resumo}

Existe no Brasil uma tendência crescente em relação ao número de ambientes de educação informal como os Museus de Ciência e Tecnologia (MCTs) e similares. Um recente levantamento indicou cerca de 190 deles no país, um número considerado relativamente pequeno para atender mais de cinco mil municípios. Aliás, essa quantidade estimada representa uma amostra heterogênea na medida em que sobressaem aqueles de grande porte somados com outros ambientes, que comparativamente, se encontram ainda em fase inicial de elaboração e ampliação de suas atividades interativas. Reconhecidas por se destacarem diferenciando-se daquelas do ensino escolar tradicional, essas atividades são costumeiramente realizadas pelos próprios visitantes numa perspectiva de livre escolha, ora por manuseio de manivelas ora por aperto de botões. Nesse contexto, o presente trabalho visa contribuir àqueles comprometidos com a educação informal desses lugares divulgando alguns dos principais dispositivos eletrônicos que podem ser facilmente montados para automatizações dos cobiçados equipamentos interativos tipo push-button, cujas aplicabilidades diversas nesse sentido são também discutidas.

Palavras-chave: Automatizações. Equipamentos. Push-button. Museus de Ciência e Tecnologia (MCTs).

\begin{abstract}
In Brazil there is a growing trend in the number of informal education settings such as Museums of Science and Technology (MCT) and others them. A recent survey indicated about 190 of them in the country, considered a relatively small number to serve over five thousand municipalities. Indeed, this represents heterogeneous group, in that, together with environments, which comparatively are still in early stages of development and expansion of their interactive activities. This activities, recognized for this differences in relation of those formal education activities, are routinely canned out by the
\end{abstract}

\footnotetext{
1 Físico do Depto de Física da Universidade Estadual de Londrina - PR. osmarh@uel.br 2 Analista de informática da ATI, Universidade Estadual de Londrina - PR. amarildo@uel.br 3 Docente do Depto de Química da Universidade Estadual de Londrina - PR. silicz@uel.br 4 Docente do Depto de Física da Universidade Estatual de Londrina - PR. irinea@uel.br
} 
visitors from the perspective of free choice, by handling cranks or grip buttons. In this context, this work aims to contribute to those committed with the places of informal education touting major electronic devices that can be easily mounted to the coveted automation equipment interactive push-button, whose applicability in different direction are also discussed.

Keywords: Automations. Equipment. Push-button. Museums of Science and Technology.

\section{Introdução}

Os Museus de Ciência e Tecnologia (MCTs) ${ }^{5}$, reconhecidos com um papel educativo de divulgar e popularizar a ciência em complementação do ensino escolar, concretizaram-se como expositores de uma multiplicidade de aparatos com os quais o público interage movimentando-os, majoritariamente, por manuseio de manivelas ou aperto de botões (ISZLAJI, 2012, p. 90). Dessa natureza em suas essências, a exposição museal em geral acabou apelidada de interatividade push-button (DAMICO, 2004, p. 25). Em tempos recentes, uma categorização mais ou menos consagrada da interatividade entre sujeitos e objetos nesses lugares, baseada em Wagensberg (2005), abrange três níveis: a interatividade hands-on - relacionada ao toque e manipulação física ${ }^{6}$; interatividade mindon - relacionada ao engajamento intelectual; e a interatividade heart-on - relacionada com a emoção e a cultura. Para a interação por manipulação, cabe então esclarecer que há o entendimento no qual ela pode ocorrer ou diretamente (hand-on) ou por meio de mecanismos acionados pelo visitante num simples aperto de botão (push-button) ${ }^{7}$ (CHELINI; LOPES, 2008, p. 232). Entendimento este de experimentação por manipulação que parece estar, segundo Colinvaux (apud CHELINI; LOPES, 2008, p. 231), na origem de muitos museus de ciências em que "a interatividade tem sido a palavra de ordem" (PAVÃO; LEITÃO, 2007, p. 44).

Tradicionalmente classificados como fornecedores de um ensino informal, MCTs (e similares) têm se expandido no Brasil ${ }^{8}$. Segundo Dentillo (2013), ainda não se tem números exatos de quantos deles existem no país, mas a Associação Brasileira de Centros e Museus de Ciência (ABCMC) está elaborando um guia atualizado. No entanto, embora um levantamento inicial de 2005 a 2009 indique o aumento de quase $73 \%$ com a expansão de 80 para 190 deles (ibid.), a quantidade é considerada relativamente pequena ao atendimento de mais de cinco mil municípios. Aliás, essa totalidade estimada representa uma amostra heterogênea na medida em que sobressaem aqueles de grande porte somados com os demais que, comparativamente, se encontram ainda em fase inicial de elaboração e ampliação de suas atividades interativas.

Mediante a meta comum de MCTs continuamente aprimorarem e ampliarem seus acervos de

${ }^{5}$ Entidades com as nomenclaturas "Museus de Ciências" e "Centros de Ciências" podem ser diferenciadas em essência (DURANT, 1992, p. 8), embora por alguma distinção feita nesse sentido ainda há entidades com ambas as finalidades pelas quais se buscou distingui-las (ibid.). Jacobucci (2006) faz uma análise das terminologias utilizadas para esses núcleos e afirma que não estão muito bem definidas (p. 13), sendo comum na literatura e coloquialmente no Brasil o entendimento de espaços idênticos (p. 14). Nesse contexto, usa-se aqui a terminologia MCT no popular entendimento de entidade com objetivo de mostrar a ciência de forma lúdica e interativa.

${ }^{6}$ Em que se almeja que o visitante "esteja no papel de cientista" ao experimentar métodos científicos ao manipular objetos, modelos ou montagens que lhe permitem entender o funcionamento e o desenrolar de processos e fenômenos, em uma perspectiva de "museu de ideias" ao longo da história da humanidade.

${ }^{7}$ Tipo de interatividade manipulativa (PADILLA, 2001, p. 123) que resulta num direcionado processo ou fenômeno a ser pensado.

${ }^{8}$ Crescimento registrado em países desenvolvidos e noutros em vias de desenvolvimento (DELICADO, 2006, p. 56). 
equipamentos interativos e visando contribuir aos envolvidos com a educação informal desses ambientes, este trabalho apresenta o processo de elaboração de uma série de dispositivos eletrônicos que podem ser empregados na automatização de equipamentos fundamentados na primordial interatividade tipo push-button que se mencionou acima ser tipicamente valorizada. Nesse sentido, também se discute uma gama de aplicações desses dispositivos em demonstrações de fenômenos físicos diversos, em que os mais variados visitantes são designados a livremente experimentarem o que lá se encontra preparado em uma perspectiva de entretenimento que tanto esses lugares anseiam (CHELINI; LOPES, 2008, p. 228-235; VALENÇA, 2006, p. 333; CAZELLI apud CONSTANTIN, 2001, p. 197) ${ }^{9}$. Tais automatizações são importantes por permitirem que todos ${ }^{10}$ facilmente realizem as demonstrações dos fenômenos com segurança por simples apertos de botão, assim como em geral possibilitam proteções, como blindagens de vidro ou acrílico, contra danos que ocorreriam nos equipamentos previsivelmente ocasionados por 'curiosidades' indesejadas em razão de eles poderem ser livremente acessados pelos visitantes no dia-a-dia. Esses aspectos, juntamente com sintéticas sugestões de elaborações de textos explicativos com linguagem acessível à maioria dos experimentadores com indução do que observar mais comandos de acionamento, serão comentados.

\section{Circuitos de controle automático: materiais utilizados, metodologia de construção e aplicações em equipamentos interativos push-button}

De acordo com o objetivo do trabalho, esta seção expõe a elaboração ${ }^{11}$ de três principais circuitos eletrônicos destinados aos equipamentos interativos tipo push-button, discutindo suas aplicabilidades gerais na automatização de demonstrações de interessantes fenômenos naturais. Os circuitos estão apresentados em figuras, cada um com seu correspondente esquema elétrico para orientação de montagem, em que a lista geral de componentes é constituída por resistores (1 $\mathrm{K} \Omega ; 10 \mathrm{~K} \Omega ; 22 \mathrm{~K} \Omega ; 100 \mathrm{~K} \Omega ; 330 \mathrm{~K} \Omega ; 1 \mathrm{M} \Omega ; 1,5$ $\mathrm{M} \Omega)$, capacitores de $16 \mathrm{~V}(10 \mathrm{nF} ; 2,2 \mathrm{uF} ; 4,7 \mathrm{uF}$; $100 \mathrm{uF} ; 1000 \mathrm{uF}$ ), circuitos integrados (CI 555; CI 4013; CI 7812), transistor (BC 548), diodo (IN 4007), transformador $\left(127^{12}\right.$ para $\left.12 \mathrm{~V}(0,5 \mathrm{~A})\right)$ e botão de acionamento (push-button tipo NA).

As três montagens discutidas podem ser feitas em chapa de circuito impresso de $(7 \times 12) \mathrm{cm}$, onde se desenham as trilhas de ligações com tinta de caneta apropriada seguindo os esquemas das figuras com posterior remoção do cobre da superfície não pintada ao mergulhar a chapa em solução de percloreto de ferro. A tinta das trilhas é removida lixando-as com lã de aço, realizando os devidos furos para encaixe e solda dos componentes. Este método mais tradicional pode ser substituído por uso de placa de circuito impresso perfurada (pré-furada), no caso de (16x10) $\mathrm{cm}$, já pronta para encaixe dos componentes citados, completando todas as ligações com fios tipo cabinho e solda estanho.

Por definição, os três circuitos de controle automático estão seguidamente especificados como CCA1, CCA2 e CCA3, conforme são apresentados. De posse dos componentes eletrônicos da lista acima, o esquema elétrico da figura 1 refere-se à orientação de montagem do CCA1.

\footnotetext{
${ }^{9}$ Para Pavão e Leitão (2007, p. 41), além do entretenimento e informação, os experimentos interativos "representam um progresso ao oferecerem certo envolvimento lúdico do público", entendimento este exemplificado por Bonatto et al. (2007, p. 49).

${ }^{10}$ Considerando o grande número de crianças nesses locais.

${ }^{11}$ Desenvolvimento alcançado por ideias em Saber Eletrônica: <http://www.sabereletronica.com.br/secoes/leitura/1595>.

${ }^{12} \mathrm{Ou} 220 \mathrm{~V}$ caso seja a tensão do equipamento focado.
} 
Figura 1 - CCA1.

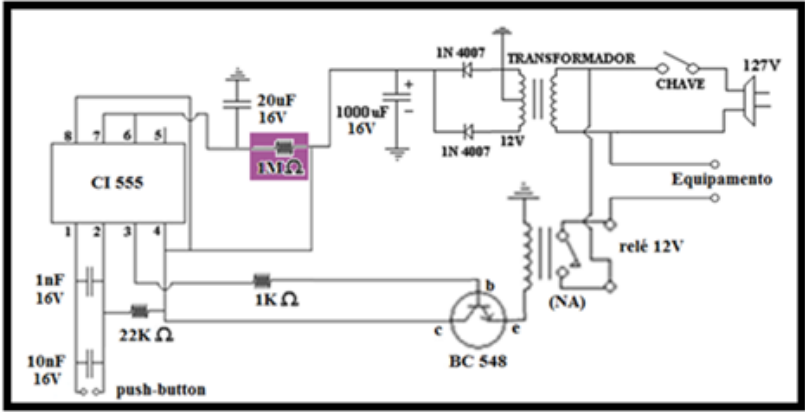

Fonte: Os autores

O dispositivo CCA1, assim como os demais, é interligado àquilo que se destina ser ativado por energia elétrica convencional $(127 \mathrm{~V})^{13}$. O CCA1, conectado à tomada padrão, fica programado a acionar a demonstração planejada por aperto do botão e, após um tempo estipulado, cessá-la automaticamente. No caso da figura 1 , o tempo de funcionamento é de cerca de 5 segundos, mas pode ser modificado ao se alterar o resistor de $1 \mathrm{M} \Omega$ ou trocando-o por um resistor variável (trimpot), cujo valor da escala em ohms dependerá do avaliado tempo de funcionamento de determinada situação ${ }^{14}$.

A figura 2 apresenta o CCA2, que se diferencia do dispositivo anterior por impedir de imediato o sucessivo acionamento da demonstração após seu término automático. O CCA2 torna-se útil em circunstâncias nas quais se caracteriza a necessidade de certo aguardo à repetição da demonstração, conforme se exemplificará mais adiante.
Figura 2 - CCA2.

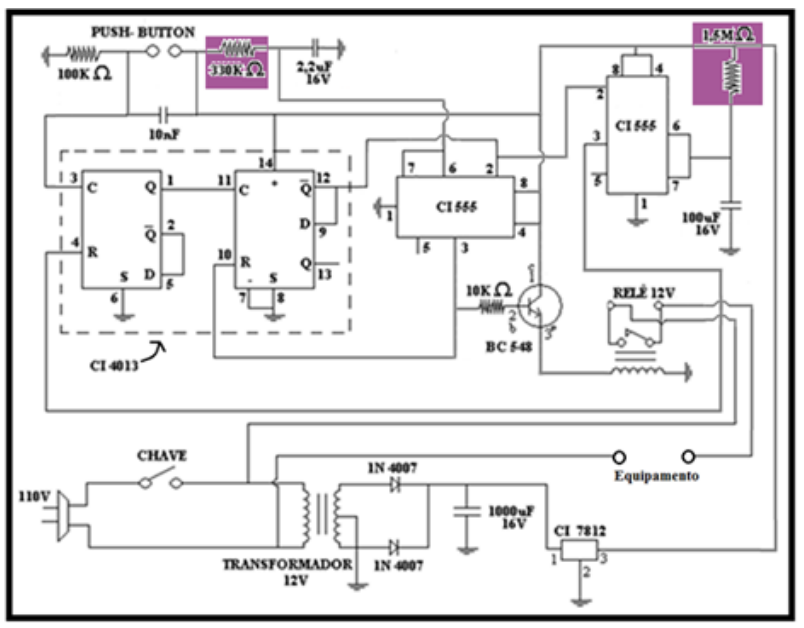

Fonte: Os autores

Pelo CCA2, ao pressionar o botão, o tempo em que esse dispositivo permitirá a alimentação de algo com a energia elétrica é ajustado por alteração do valor do resistor de $330 \mathrm{~K} \Omega$ (ou do capacitor de 2,2 $\mathrm{uF}$ ). Então programado o tempo de funcionamento, nada ocorrerá após o desligamento automático se um experimentador novamente pressionar o botão, pelo menos até que o devido tempo de espera tenha transcorrido. Por sua vez, essa duração da espera a um novo acionamento é determinada conforme se substitui o valor da resistência de 1,5 $\mathrm{M} \Omega$ (ou do capacitor de $100 \mathrm{uF}$ ).

Já o próximo dispositivo CCA3 (figura 3) diferencia-se dos demais na medida em que, num primeiro momento quando se aperta o botão, ele ativa a demonstração por energia elétrica padrão $(127 \mathrm{~V}$ ou $220 \mathrm{~V})$ em um tempo estipulado ${ }^{15}$ e, após o término, automaticamente aciona um outro elemento (no caso do esquema, projetado para $12 \mathrm{~V}$ (DC)),

${ }^{13}$ Se for $220 \mathrm{~V}$, basta substituir o transformador especificado na figura 1 por outro com entrada de $220 \mathrm{~V}$ e mesma saída de $12 \mathrm{~V}$. Procedimento este válido aos três dispositivos apresentados.

${ }^{14}$ De modo análogo à substituição do resistor de $1 \mathrm{M} \Omega$, muda-se o tempo de funcionamento por uso de valores diferentes aos do capacitor de $20 \mathrm{uF}$.

${ }^{15}$ Nessa finalidade, pode-se alterar o valor especificado da resistência de $330 \mathrm{~K} \Omega$ ou o da capacitância de $2,2 \mathrm{uF}$. 
cujo tempo de alimentação tem o procedimento de acerto equivalente aos já mencionados ${ }^{16}$. Dessa montagem, durante a alimentação desse elemento (em $12 \mathrm{~V}$ ), a programação eletrônica impede o acionamento daquilo que inicialmente fora ativado pelos $127 \mathrm{~V}$ (ou $220 \mathrm{~V}$ ). Logo, nada de imprevisto ocorrerá se alguém prosseguir com repentinos acionamentos do botão, situação essa válida para as distintas programações dos dispositivos anteriores.

Figura 3 - CCA3.

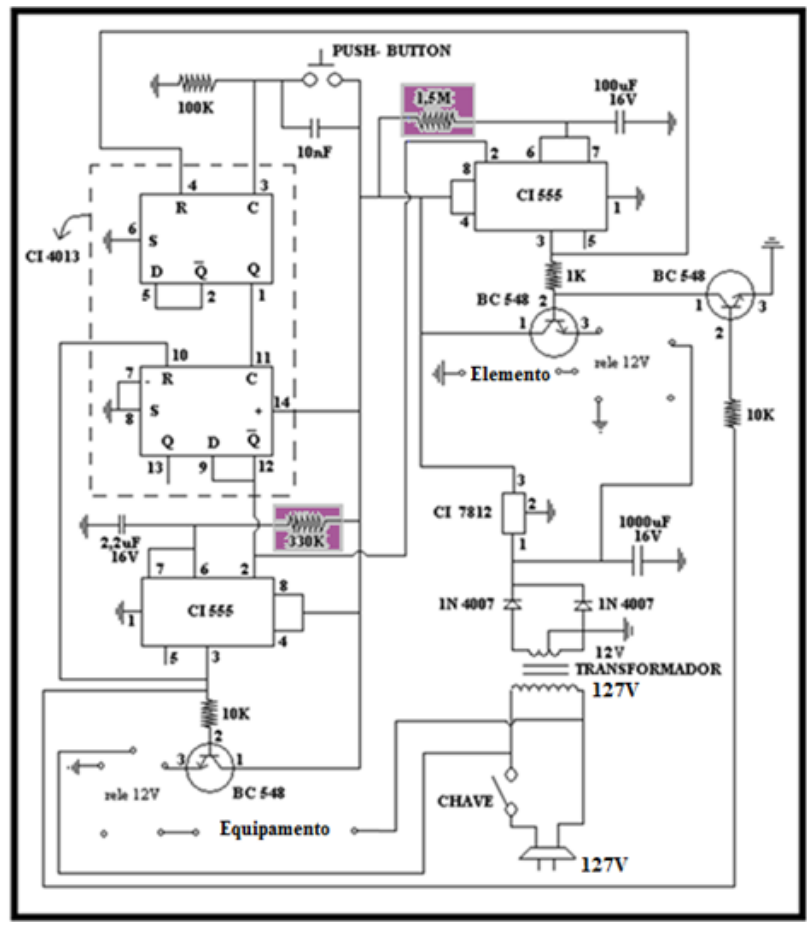

Fonte: Os autores

Os três dispositivos apresentados estão projetados para permanecerem continuamente conectados à tomada $(127 \mathrm{~V}$ ou $220 \mathrm{~V})$, sendo a chave ligadesliga nas figuras opcional. Em termos aplicativos, busca-se abaixo discutir alguns empregos desses dispositivos em equipamentos interativos tipo pushbutton.

O CCA1, pela única tarefa do desligamento automático da alimentação de energia elétrica, tem uma ampla possibilidade de uso a tudo que se projeta ser movimentado ou dependente dessa forma de energia cotidianamente disponível. Seguindo o esquema da figura 1, pode-se, por exemplo, ligar um motor elétrico onde está mencionado 'equipamento'. Como exemplo, vale citar a montagem que usa um motor (preferivelmente de indução, neste caso, por questão de segurança) onde se acopla um disco de Newton para girá-lo e demonstrar a composição da cor branca pela superposição das cores do seu espectro ${ }^{17}$. Em outro caso, pode-se adaptar o CCA1 a um transformador de alta tensão, muito usado na demonstração denominada "Faiscador de Chifre" (ou "Chispa ascendente"), que proporciona uma fascinante descarga elétrica no ar entre dois terminais condutores. Essas demonstrações são bem conhecidas e diversas montagens estão disponíveis na internet, ficando o CCA1 com a função da automatização já mencionada, cujo tempo de desligamento é programado a cada situação. A figura 4 apresenta um "Disco de Newton" e um "Faiscador de Chifre"18, os dois adaptados com o CCA1. Vale observar que as demonstrações são comumente projetadas para serem observadas do lado de fora de um tipo de caixa protetora que tem pelo menos uma parte frontal transparente apropriada aos equipamentos, estando a manipulação do experimentador restringida à ativação de cada um deles por aperto do botão push-button do $\mathrm{CCA}^{19}$, dispositivo este que se deixa escondido em algum local no interior da estrutura (caixa).

\footnotetext{
${ }^{16}$ Conforme procedimento da nota de rodapé anterior relativo agora aos componentes de 1,5 $\mathrm{M} \Omega$ e $100 \mathrm{uF}$.

${ }^{17}$ Considerando o tempo de permanência da imagem na retina.

${ }^{18}$ Todos os equipamentos aqui relatados pertencem ao MCT da instituição onde se encontram os autores do trabalho.

${ }^{19}$ Assim como aos dispositivos CCA2 e CCA3.
} 
Figura 4 - Disco de Newton (lado esquerdo) e Faiscador de Chifre (lado direito) ${ }^{20}$.

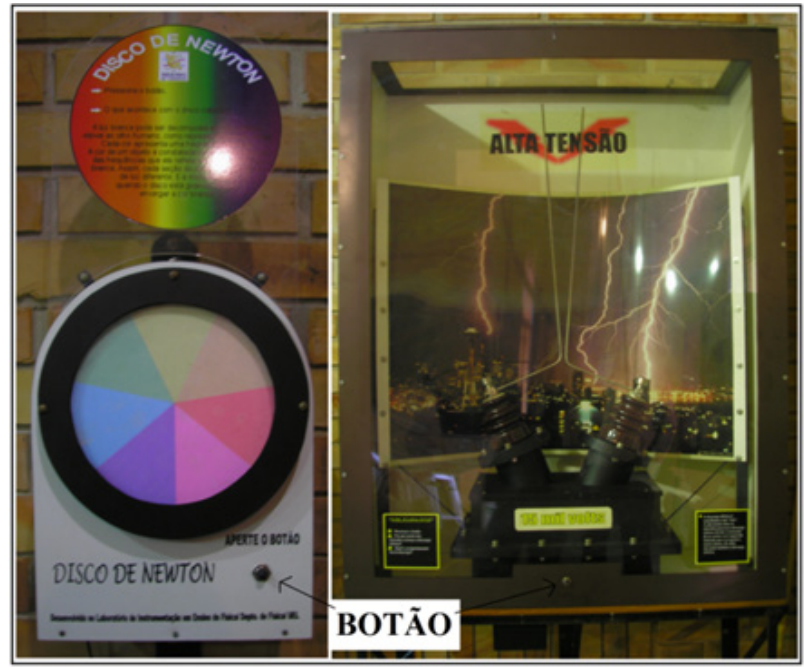

Fonte: Os autores

Por sua vez, uma das aplicações do CCA2 está no experimento "Pêndulo de Ressonância", cuja montagem $^{21}$ insere um eletroímã escondido para atrair a massa do pêndulo para baixo e iniciar a demonstração da ressonância. No caso, ao pressionar o botão, o CCA2 liga o eletroímã num curto intervalo de tempo e impede um novo acionamento até o término da demonstração. Impedimento este que ali se faz necessário para não afetar ${ }^{22} \mathrm{o}$ efeito ressonante que se objetivou ser apreciado pelo experimentador.

Referindo-se ao CCA3, pode-se dizer que ele se torna indicado a situações mais incomuns comparadas às dos anteriores. $\mathrm{O}$ dispositivo foi inicialmente desenvolvido para automatizar um equipamento de levitação eletrodinâmica, na medida em que ele ativa a corrente elétrica de uma bobina para sua flutuação, elevando, naturalmente com isso, sua temperatura em demasia. Isto faz com que a bobina logo precise ser desligada e refrigerada por ventilação para adiantar a disponibilidade de nova demonstração. Portanto, a função do CCA3 neste equipamento específico é de ativar, por um único aperto do botão, a flutuação da bobina num curto intervalo de tempo e, no mesmo instante que a desliga automaticamente, também aciona uma série de ventoinhas $(12 \mathrm{~V})$ que aceleram sua refrigeração natural enquanto permanece desligada. Como apresentado na figura 3, o CCA3 encontra-se adaptado a esse equipamento de levitação comentado, mas com uma ligeira modificação no circuito, ele pode acionar um segundo elemento qualquer (que não as ventoinhas) de outra tensão particular e/ou desejada. Como exemplo, a figura 5 expõe uma parte do CCA3 na qual se faz uma mudança nas ligações para permitir uma alimentação do elemento com $127 \mathrm{~V}$ e, se for necessário $220 \mathrm{~V}$, pode-se seguir mais a orientação da nota de rodapé 9 .

Figura 5 - (A) Ligações do CCA3 da figura 3 que são excluídas. (B) Ligações acrescentadas.

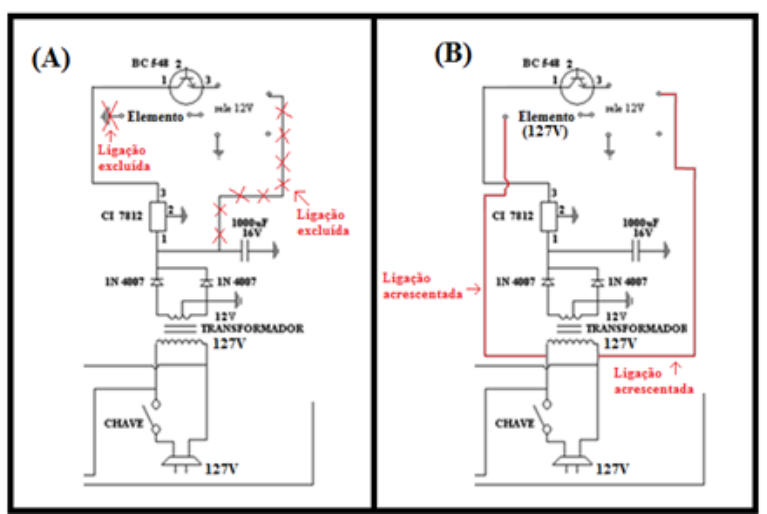

Fonte: Os autores

${ }^{20}$ Em Silva; Zaparolli e Arruda (2012), há uma aplicação modificada do CCA1 para acionar, por meio de dois botões, um laser de $3 \mathrm{~V}$ e um motor de $24 \mathrm{~V}$ que controla a rotação de uma lente num equipamento demonstrativo de óptica geométrica, cuja construção completa é relatada. Lá (idid.) pode-se notar a simplicidade de tal modificação à especificidade da demonstração.

${ }^{21}$ Montagens de pêndulos de ressonância são conhecidas e divulgadas na internet, mas as peculiaridades dessa em particular são encontradas em Silva et al. (2013).

${ }^{22}$ Pensando na hipótese de um experimentador 'indiscreto' ficar seguidamente apertando o botão, o que prejudicaria a demonstração do fenômeno de ressonância por acionamentos repentinos do eletroímã. 
Os três dispositivos assim apresentados são importantes por permitirem a adequação de muitas demonstraçõesàs condições educativas informais que aqui se atenta, ponderando essenciais preocupações de montagem com automatizações push-button: individualmente, qualquer experimentador deve obter sucesso nas demonstrações, realizando-as de forma lúdica, segura e fácil; constituídos de uma típica "blindagem" transparente, os equipamentos ficam protegidos de avarias que podem ocorrer devido a algum manuseio impróprio ou falta de zelo de 'determinados' visitantes.

Todavia, a crítica particular à interatividade tipo push-button é a possibilidade de ela ocorrer como "compulsão psicomotora" ao se apertar o botão, sem que o experimentador ao menos espere a conclusão do efeito gerado nem se deixe alargar sua percepção e cognição, haja vista que a resposta é única e não é possível fazer funcionar diferente a fim de se testar uma hipótese (MASSABKI, 2011, p. 62). Vale esclarecer que este último caso não é tido como alternativa superior, uma vez que Eason e Linn (apud GASPAR, 1993, p. 145) ressaltam a comprovação de diferença não significativa no grau de aprendizagem entre interatividades push-button e "hands-on". Para outra comparação mais bem detalhada, Studart (2003, p. 35) descreve as investigações de Blud com cinquenta grupos de indivíduos que participaram de uma exposição completamente interativa, uma do tipo "aperta-botão" e uma estática, concluindo que não houve diferença significativa de aprendizado de conteúdos específicos entre os participantes de cada uma das três exposições, apesar de as primeiras promoverem mais discussões. Considerando isso, cabem aos equipamentos interativos push-button textos explicativos específicos a eles anexados que contribuem para uma clareza de entendimento, pois, conforme Gaspar (1993, p. 148), “os visitantes, na sua maioria, leem os textos apresentados pelo menos até que tenham uma ideia do objetivo ou proposta da demonstração".

Cada texto em particular precisa ser aperfeiçoado a critério do aprofundamento determinado na linguagem das explicações científicas em termos qualitativos ou não. Além do destacado comando "Pressione o Botão", os esclarecimentos dos fenômenos são direcionados ao público alvo, majoritariamente formado por estudantes do nível básico de ensino e leigos em geral ${ }^{23}$. Nesse sentido, mesmo que qualquer elaboração deste tipo permaneça alvo de melhorias, é significativo dizer que a essência desta orientação explicativa, que se recomenda atrelar nos equipamentos, mantémse conservada. Mais ainda, dentro da perspectiva lúdica de interação com os equipamentos, esperase possibilitar que os fenômenos observados sejam posteriormente bem resgatados da memória de um estudante em situações de sala de aula nas quais um assunto abordado tenha sido por ele relacionado, permitindo que o educador possa então usufruir de tais lembranças em melhoria do aprendizado dos conceitos científicos envolvidos no decorrer das discussões.

\section{Considerações finais}

MCTs constituem um dos principais instrumentos das políticas de promoção da cultura científica nas últimas duas décadas (DELICADO, 2006, p. 56). Em geral, eles permanecem com acervos de experimentos interativos sendo muitos destes identificados como: "um aparelho que incorpora principios fisicos elou tecnológicos fundamentais, em que os visitantes são encorajados a 'brincar'com este aparelho num mínimo de orientação textual ou mediadora possível, a fim de que a informação se

\footnotetext{
${ }^{23}$ Alguns modelos de elaborações de textos explicativos podem ser vistos em Silva, Zaparolli e Arruda 2012 e Silva et al. (2013).
} 
faça clara apenas com a 'descoberta' do visitante" (DURANT, 1992, p. 8). Análises educacionais à parte, fato é que a interatividade almejada nesses ambientes abrange diferentes tipos e graus: alguma ocorre "com aperto de botão e algo acontece" (tipo push-button); noutra se abre um compartimento para notar uma informação escondida; outras são jogos de perguntas e respostas ou quebra-cabeças. Embora haja diferentes filosofias relacionadas aos parques de ciência, uma comum concepção pode ser exemplificada na preparação de um pequeno Museu de Ciência no Brasil, na qual, pela argumentação de um dos professores envolvidos no projeto, se reconhece que "as pessoas não vão ao museu para aprender sobre física ou outra ciência" ${ }^{24}$ (REIS, 2008). Segundo ele:

É preciso dar ao visitante a liberdade de ser guiado por sua curiosidade e, se ele quiser dirigir perguntas aos monitores, proceda dessa forma. Ou simplesmente experimenta e interage com aquilo que chama mais sua atenção, fica sensibilizado com os equipamentos e acaba tomando contato com um novo vocabulário. (ibid.)

Este estudo indicou a tendência crescente do número de MCTs (e similares) no Brasil e, nesse caminho, grande parte deles (ex.: ibid.) costuma adquirir seus "brinquedos" educacionais por meio de fabricantes específicos que os comercializam a um custo considerável ou mesmo de 'admirados' MCTs que possuem uma equipe técnica habilitada em fabricá-los. Este último caso é lembrado por um dos autores do presente trabalho quando participou de um evento nacional realizado no MCT da PUC/RS, relacionado ao design e construção de equipamentos interativos. Diante disso, o presente trabalho apresentou processos de construção de circuitos de automatização eletrônica para três tipos diferenciados de funções, que podem ser aplicados à simulação de diversos fenômenos naturais. Por um comparativo, tem-se popularizado a placa Arduino ${ }^{25}$ (SOUZA et al., 2011) como um referencial moderno, de baixo custo, e que pode vir a realizar as funções desses circuitos. Todavia, o custo de uma dessas placas ainda é mais que o dobro, por exemplo, do CCA1 (rapidamente montável em placa perfurada), em que uma pesquisa de mercado indicou respectivos valores médios de $\mathrm{R} \$ 75,00 \mathrm{e}$ $\mathrm{R} \$ 32,00$. Logo, os dispositivos aqui apresentados demonstram-se como uma alternativa interessante à comunidade de profissionais atuantes em pequenos e médios museus e centros de ciência, estando em fase inicial de elaboração ou não, que seguem a meta de continuamente aprimorarem e ampliarem seus acervos de equipamentos interativos numa perspectiva de entretenimento e simulações.

Para tanto, discutiu-se as empregabilidades dos três dispositivos eletrônicos em equipamentos didático-científicos desses ambientes educativos informais para que as demonstrações relacionadas sejam facilmente acionadas por simples apertos de botões. Objetivou-se limitar as discussões de suas aplicabilidades exemplificando-as em equipamentos demonstrativos de conceitos físicos, justificável pelo comentário de Pavão (AGÊNCIA CIÊNCIA WEB, 2009): “A Física, talvez pela facilidade dessa interatividade por manipulação, historicamente tem sido a grande atração nos museus de ciência". De todo modo, vale a criatividade para a generalização de tais aplicações em demonstrações de conceitos de outras áreas científicas que os interessados julgarem convenientes.

${ }^{24}$ Em defesa desse posicionamento pode-se destacar a fala do diretor da ABCMC, Antônio Carlos Pavão: "os centros e museus de ciência não são espaços para aprender ciência, mas sim para estimular o interesse dos estudantes. À escola cabe o papel de organizar esse conhecimento" (AGÊNCIA CIÊNCIA WEB, 2009).

${ }^{25}$ Baseada num microcontrolador operante no controle de vários dispositivos e com aplicações em instrumentação embarcada e robótica (SOUZA et al., 2001, p. 1701-1). 


\section{Referências}

AGÊNCIA CIÊNCIA WEB (Agência Multimídia de Difusão Ciêntífica e Educacional - IEA/ USP). Museus de Ciência: o conhecimento de forma divertida. 2009. Conteúdo Jornalístico. Disponível em: <http://agenciacienciaweb. wordpress.com/2009/02/06/museus-de-ciencia-oconhecimento-de-uma-forma-divertida/ $>$. Último acesso: 25/05/2013.

BONATO, M. P. O.; SEIBEL, M. I.; MENDES, I. A. Ação mediada em museus de ciências: o caso do Museu da Vida. In: Massarani, L; Merzagora, M.; Rodari, P. (Orgs.). Diálogos \& Ciência: mediação em museus e centros de Ciência. Rio de Janeiro: Museu da Vida/ Casa de Oswaldo Cruz/ Fiocruz, 2007.

CHELINI, M. E.; LOPES, S. G. B. C. Exposições em museus de ciências: reflexões e critérios para análise. Anais do Museu Paulista, v. 16, n. 2, p: 205238, jul-dez, São Paulo, 2008.

COnStAntin, A. C. C. Museus interativos de ciências: espaços complementares de educação? Interciencia. V. 26, n. 5, pp. 195-200, mayo (2001).

DAMICO, J. S. "Uma nova relação estrutural para a sustentabilidade do Museu da Vida". 2004. Dissertação (Mestre em Gestão de Ciência) - Escola Nacional de Saúde Pública Sérgio Arouca, Rio de Janeiro.

DELICADO, A. Os museus e a promoção da cultura. Sociologia, Problemas e Práticas, Oeiras, n. 51, p. 53-72, 2006.

DENTILLO, D. B. Centros e museus crescem, mas investimento ainda é insuficiente. Ciência e cultura, São Paulo, v. 65, n. 2, p. 12-13, abr./jun. 2013. Disponívelem: $<$ http://cienciaecultura.bvs.br/scielo. php?pid=S0009-67252013000200005\&script=sci arttext>. Acesso em: 11 jun. 2013.

DURANT, J. Museums and the public understanding of science. London: NMSI Trading Ltd, Science Museum, 1992.
GASPAR, A. Museus e centros de ciências: conceituação e proposta de um referencial teórico. 1993. Tese (Doutorado em Didática) - Universidade de São Paulo, São Paulo.

ISZLAJI, C. A criança nos museus de ciências: análise da exposição mundo da criança do museu de ciência e tecnologia da PUCRS. 2012. Dissertação (Mestre em Ensino de Ciências) - Universidade de São Paulo, São Paulo.

JACOBUCCI, D. F. C. A formação continuada de professores em centros e museus de ciências no Brasil. 2006. Tese (Doutorado em Educação) Universidade de Campinas, Campinas.

MASSABKI, P. H. B. Centros e museus de ciência e tecnologia. 2011. Dissertação (Mestre em Arquitetura) - Universidade de São Paulo, São Paulo.

REIS, A. UFSC inicia montagem de pequeno museu de ciência. Santa Catarina, 2008. Disponível em: <http://noticias.ufsc.br/2008/06/ufsc-iniciamontagem-de-pequeno-museu-de-ciencia/ $>$. Acesso em: 12 jun. 2013.

PADILla, J. Conceptos de meseos y centros interactivos. In: CRESTANA, S. et al. (Org.). Curso para treinamento em centros e museus de ciência: educação para a ciência. São Paulo: Livraria da Física, 2001. p. 113-141.

PAVÃO, A. C.; LEITÃO, A. Hands-on? Mindson? Herts-on? Social-on? Explainers-on! In: MASSARANI, L; MERZAGORA, M.; RODARI, P. (Org.). Diálogos \& Ciência: mediação em museus e centros de ciência. Rio de Janeiro: Museu da Vida, 2007. P. 39-48.

SABER ELETRÔNICA. Saber eletrônica: o seu portal para o universo da eletrônica. Disponível em: <http://www.sabereletronica.com.br/secoes/ leitura/1595>. Acesso em: 28 abr. 2013.

SILVA, N. C. UFSC inicia montagem de pequeno museu de ciência. Notícias da UFSC. 2008. Disponível em: <http://noticias.ufsc.br/2008/06/ ufsc-inicia-montagem-de-pequeno-museu-deciencia/>. Último acesso: 12 de junho de 2013. 
SILVA, O. H. M.; ARRUDA, S. M.; LABURÚ, C. E.; BUENO, E. A. S. Pêndulo de Wilberforce: uma proposta de montagem para ambientes educativos informais e laboratórios didáticos. Caderno Brasileiro de Ensino de Física, Florianópolis, v. 30, n. 2, p. 409-426, ago. 2013.

SILVA, O. H. M.; ZAPAROLLI, F. V. D.; ARRUDA, S. M. Demonstrações em óptica geométrica: uma proposta de montagem para ambientes de educação não formal. Caderno brasileiro de ensino de física, Florianópolis, v. 29, n. 3, p. 1199-1199, dez. 2012.

SOUZA, A. R.; PAIXÃO, A. C.; UZÊDA, D. D.; DIAS, M. A.; DUARTE, S.; AMORIN, H. S. A placa Arduino: uma opção de baixo custo para experiências de física assistidas pelo PC. Revista Brasileira de Ensino de Física, São Paulo, v. 33, n. 1, p. 1701-05, 2011.

STUDART, D. C. Famílias, exposições interativas, e ambientes motivadores em museus: o que dizem as pesquisas? Avaliação e estudos de públicos no museu da vida. Rio de Janeiro: Museu da Vida, 2003.

VALENÇA, V. L. C. A criação do museu das crianças de Santa Catarina: uma experiência em andamento. Perspectiva, Florianópolis, v. 24, n. 1, p. 319-338, jan./jun. 2006.

WAGENSBERG, J. O Museu "Total”, uma ferramenta para a mudança social. In: CONGRESSO MUNDIAL DE CENTROS DE CIÊNCIA, 4., 2005, Rio de Janeiro. Anais... Rio de Janeiro, 2005. p. 1-19.

Recebido em 9 Maio, 2014 - Received on May 9, 2014

Aceito em 9 Julho, 2014 - Accepted on July 9, 2014 